\title{
SIGNIFICANCE OF THE BEHAVIOR OF SENSITIVE STIGMAS II.
}

\author{
F. C. Newcombe
}

(Received for publication May I4, I923)

In a previous paper by the author (9), the experimental study of the closing phenomena of the sensitive stigmas of five species of plants led to the conclusion that the so-called primary closing aids in cross-pollination, and the so-called secondary closing promotes the germination of pollen on the stigma. The first of these conclusions had been reached by earlier investigators, though not without some dissent, and the second conclusion was without positive support. Within the past two years, there has been opportunity to extend observations and experiments to several other species with sensitive stigmas, and the results of the later study are recorded in the following pages.

\section{Observations AND Experiments}

Spathodea campanulata Beauv. Growing on the campus of the University of Hawaii, Honolulu, is a group of beautiful young African tulip trees, which bloomed abundantly in August, I92 I, showing great racemes of tulip-like, bright red blossoms. This member of the Bignoniaceae has the bilabiate stigma and the didynamous anthers characteristic of that family. The style is negatively geotropic and generally places itself and the stigma between the cluster of stamens and the upper side of the corolla. The flowers open in early morning and remain fresh for eight hours to several days, according to the moisture in the atmosphere. It was a common sight to see all flowers that had opened in the morning wither before sunset of the same day. In the flowers observed, the stigma lobes separated from one another $90^{\circ}$ to $180^{\circ}$ as the flowers opened; the anthers opened, in flowers brought to the house, two to three hours later than the opening of the stigma. Self-pollination is thus rendered unlikely both by the proterogynous habit and by the position of the stigma. About one third of all the flowers set seed, though no insects nor birds were observed about the flowers. Close watch for insect or bird visitors was not made. One may well believe that the flowers have visitors in their native habitat at least, for there is such an abundance of honey that it runs out in several drops when the flower is forcibly inverted.

For experimental purposes, 35 flowers, soon to open, were plucked in the evening of different days and taken to the house. Here each flower pedicel was cut through under water, and the flowers stood upright in cups with the pedicels in water. The temperature indoors was $25^{\circ}$ to $27^{\circ} \mathrm{C}$., and the air was fairly moist. Such flowers retained their freshness for three 
to four days. Pressure by the finger tips or by a folded blade of grass on the inner surfaces of the stigma lobes never caused closing. In some cases there was a slow movement of the lobes, but only through $10^{\circ}$ to $15^{\circ}$. Pollen in abundance was placed on the stigmas of 4 flowers without pressing the stigmas; subsequently none of the stigmas closed though the flowers were watched for three days. On the open stigmas of 5 flowers abundance of pollen was pressed with the tip of the finger. One stigma closed slowly after the lapse of 50 minutes, another after 60 minutes, and a third after 4 hours. The other 2 stigmas did not close. All 5 stigmas kept these positions unchanged until withering. Three open stigmas had pollen applied with the tip of the finger. None closed immediately, but all 3 were closed 20 minutes after pollination and did not subsequently open.

Quite different is the behavior of pollinated stigmas remaining uncovered on the tree. Six open stigmas had pollen pressed on their inner faces by the tip of the finger at I I o'clock a.m. One closed in five minutes, and the other 5 closed in periods between 5 and 10 minutes. The temperature was $27^{\circ}$. This is the shortest period for closing seen in this species. Indoors, the shortest period was 20 minutes. These 6 closed stigmas did not subsequently open.

The stigmas of this species can not be made to close by pressure alone. At least in the scores of trials I have made with flowers, both on the tree and indoors, I have never seen the stigma lobes approach nearer to one another than $50^{\circ}$ though the stimulation was repeated Io times within ro minutes. In the majority of cases of attempted closing of stigmas indoors by gentle pressure of the finger tip or by the blunt tip of a wooden style, no response could be detected. In flowers in warmer air, as on the trees, one could usually detect a movement of the lobes of $5^{\circ}$ to $30^{\circ}$. The shortest latent period observed was 5 seconds.

Wheat flour, when pressed upon the inner faces of the lobes of 3 stigmas by the tip of the finger, caused one stigma to close completely in $20 \mathrm{~min}$ utes, one to close to an opening of $10^{\circ}$, and the third to an opening of $20^{\circ}$. After 3 hours, the one that had closed completely was open $45^{\circ}$, the other two were completely open. Two hours later, the first stigma had begun to close again, and it continued its movement till completely closed. The others remained continuously wide open. Three stigmas on which wheat flour was allowed to fall gently so as to cover the whole inner surfaces of the lobes did not show any closing movement though observed for I I hours.

Sixteen newly opened flowers were tagged on the trees in early morning, and so left undisturbed; in the evening 4 of the stigmas were found closed while the other I2 stigmas were wide open, though several of them were shriveling. This proportion of closed stigmas is about the same as the proportion of fertile to unfertile ovaries, and is probably significant.

Eleven stigmas previously pollinated, in flowers kept in the house, were examined for germination of pollen. Six of these were examined 
microscopically six and one half hours after the pollen was placed on the stigmas. Three of the stigmas had been closed six hours and ten minutes, and three had not closed at all. From the closed stigmas, the pollen grains were all swollen and pollen tubes were abundant, from those beginning to protrude to those of a length of ten times the diameter of the pollen grains. The pollen from the open stigmas showed the strongest contrast; there were but a few very short tubes, and the most of the grains had not swollen. Five other stigmas that had received pollen from the tip of the finger $3 \mathrm{I}$ hours before were also examined for germination of pollen. Three of these stigmas had been continuously closed for 29 hours or more, and 2 had not been closed at all. Germination had taken place on all 5 stigmas; but from the closed stigmas the pollen tubes were many and long, while they were few and shorter from the open stigmas. Many pollen grains had not germinated at all. All these germination experiments were made indoors; unfortunately, such tests were not made on the flowers in their outdoor environment where the conditions for drying pollen and stigmas were more intense.

Two other members of the Bignoniaceae found in Honolulu were tested merely for sensitiveness of stigma. The shrub Tecoma stans Juss. has the bilabiate stigma usual in this family. Probing the flower with a small wooden style, the stigma was found very sensitive, closing in 3 seconds when the temperature was $28^{\circ}$.

The calabash tree, Crescentia cujete L., has solitary greenish yellow flowers 6 to $8 \mathrm{~cm}$. long, with very large stigma lobes. I found but a single tree in bloom and could reach but 4 flowers. The stigmas when stimulated by pressure of the finger tip closed slowly, requiring to to I 5 seconds to effect complete closing. The temperature was $27^{\circ}$.

In May, I92 I, Diplacus glutinosus Nutt. was found flowering in abundance in the hills to the east of Palo Alto, California. This plant belongs to the Martyniaceae, and the behavior of its stigma has been well described by Lloyd (5). There is only one feature in the reactions of the stigma of this plant that need be added to what is already published. Nine flowers whose stigmas had been given pollen and closed were kept in an open room at an average temperature of $20^{\circ}$ for 12 hours after the primary closing. The stigmas had been continuously closed for at least 6 hours after the secondary closing. The cut stems bearing the flowers had been standing in water and all were fresh. They were now placed in a damp chamber at the same temperature as before. After 3 hours, 3 stigmas had opened and 3 others were opening. Fourteen hours after pollination, there was little change. Thirty hours after pollination, 6 were open and 3 closed. Ten hours later, another stigma had opened, while the other two remained closed.

\section{Discussion}

Spathodea campanulata shows, in the behavior of its stigma, an interesting variation from that of all other members of the family Bignoniaceae 
so far reported, in that the stigma lobes, though sensitive to pressure, do not close completely on pressure stimulation. The closing mechanism is in a preliminary or in a degenerate stage of development. In favorable outdoor conditions a movement of the stigma lobes may be observed 5 seconds after applying suitable pressure. Similar pressure on the stigma in the cooler and moister air indoors usually brings no noticeable response; or, if there is a movement, the angular distance traversed is less. Stigmas pollinated with the use of pressure while the flowers were on the tree closed in 5 to $10 \mathrm{~min}$ utes. Indoors, the closing, under similar treatment, required as a minimum 20 minutes and as a maximum 80 minutes, while some stigmas never closed. If pollen is placed on the stigma without pressure, while the flowers are indoors, there is no subsequent closing. Stigmas once closed, after placing pollen on them with pressure, have never been observed to open.

From the foregoing remarks, it is evident that the first and only closing of the stigma of Spathodea is due to pressure and the action of pollen combined; neither alone can cause closing. It may be that the closer contact between pollen and the stigma following application of the pollen by the finger tip is a condition for closing. If so, the closing would probably then be due to causes giving the secondary closing in other species, and not at all to response to pressure. The fact that a stigma was caused to close completely in 20 minutes when wheat flour was pressed on it with the finger tip, while flour alone without pressure never causes closing, lends some probability to the view. That this closing of the stigma waits for the germination of the pollen on the stigma, as believed by Lutz (6) to be true for all species in their secondary closing, evidently does not hold for Spathodea; for the closing on the tree, following in 5 to ro minutes after forcibly applying pollen, is far too early for germination of the pollen. Nor does the quantity of pollen, given without pressure, determine the closing in Spathodea, as Lutz found for Mimulus; for, without pressure, no amount of pollen will cause the closing of the stigma in Spathodea.

The failure of the stigma of Spathodea to open after the first closing is the usual behavior of the stigma of Tecoma radicans also, though the stigmas of most species, as recorded in literature, open Io or more minutes after pollination with pressure, to make the secondary closing an hour or more later. But the first closing of the stigma of Tecoma radicans is a sensitive response to pressure, requiring but a few seconds for the process; the first and only closing of the stigmas of Spathodea is not wholly, at least, a response to pressure, for pressure alone will not close the stigma and it requires 5 to 80 minutes to close when pollen is given with pressure.

Lutz brings some evidence to show that, in natural conditions, it is the abstraction of water from the interior cells of the stigma lobes, coupled with the carrying of some injurious chemical by the penetrating pollen tubes to the interior cells, which causes and maintains the secondary closure. He found that extract of any kind of pollen, even boiled extract, 
would cause permanent closing of the stigma of Mimulus cardinalis. A few hours after the secondary closing of pollinated stigmas, he found the stigma tissue so disorganized as to be incapable of causing the stigma lobes to open. That such conditions do not obtain for the stigmas of all species with sensitive stigmas is shown by the behavior of Diplacus glutinosus as cited in this paper. Nine flowers whose stigmas had been pollinated and had gone through their primary and secondary closing were put into a damp chamber 6 hours after the final closing. Three hours later, 3 stigmas had fully opened and 3 others had started opening. Fourteen hours after pollination there was little change. Thirty hours after poilination, 6 stigmas were fuily open, and within the next ro hours one other stigma opened. Inasmuch as pollen germination takes place 2 to 4 hours after the stigmas close, it is seen that the stigmas are capable of opening in moist air 5 to 30 hours after pollen germination.

While the evidence from all sources seems to indicate that the secondary closing and the continued closure thereafter are immediately due to an increase of permeability of the protoplasm, by which the cell turgor is lost, it is probable that detailed study will show, as is usual in the progress of science, that different species show variations in both causal and responsive phenomena.

As far as my knowledge goes, Lutz was the first author to distinguish a primary and a secondary closing of sensitive stigmas. The primary closing has by several authors been recognized as a means against selfpollination, and I have given evidence in a previous paper to show that the secondary closing promotes, and in some species, in dry air, is a necessary condition for, the germination of the pollen. Study of this subject has now gone far enough for us to recognize the fact that, while most of the species show both primary and secondary closing, there are some species which show primary and no secondary, and there are others which show secondary and no primary closing. Strobilanthes anisophyllus as determined by Morren (8), Strobilanthes isophyllus as determined by Trelease (10), Strobilanthes dyerianus as implied by Goebel, and Utricularia vulgaris as shown by Hildebrand (3) have only one functional lip to the stigma, the other being rudimentary. The stigmas of these 3 species are very sensitive to pressure and give the primary closing movement by which the receptive surface is removed from the usual path of a penetrating insect. None of these species can enclose the pollen, for only one stigma lobe is present. The 2-lobed stigma of Mimulus glabratus var. Jamesii was found by my examination to go through the primary closing, but not the secondary. The flower of this plant has a closed throat. The stigma of Spathodea campanulata closes but once, and this closing is the secondary closing of most sensitive stigmas, or, possibly, this stigma combines both closings in one.

The question has been debated by various authors, and especially by Goebel (2), as to the possible advantage to the plant of these two distinct 
closures. From the variation in the behavior of the stigmas of different species as cited above, it is evident that it is idle to attempt to bring all species under a single rule of action. In working on this problem, authors have given too little attention to the differing habitats of the species concerned, and to the capability of pollen for self-fertilization. The ecology of the behavior may not be fully demonstrated, as pointed out by Goebel (2), but certain phenomena of behavior have been ascertained.

One fact of behavior is the secondary closing of the stigmas in all species examined except in the four unusual cases mentioned in the last paragraph. And the significance of this behavior is fairly well shown by the relations as summarized in the following narrative: Catalpa speciosa ${ }^{1}$, Tecoma radicans, Torenia fournieri, Mimulus cardinalis, and Diplacus glutinosus open and remain open after the primary closing if the air about them is very moist; they make the secondary closure and remain closed if the air about them is dry. In the closed flower of Mimulus glabratus var. Jamesii, in which the air is always moist around the stigma, there is never any secondary closing. In Spathodea campanulata, no secondary opening was seen in either moist or dry air, though it should be said that the experiment of using very moist air was not attempted. There can be no doubt that the secondary opening and closing are related to the amount of moisture in the air.

Because Lloyd with Diplacus glutinosus and Lutz with Mimulus cardinalis found pollen germinating on open stigmas, Goebel (2) draws the rather hasty conclusion that the secondary closing cannot be of much significance in the biology of the plants. But neither Lloyd nor Lutz makes mention of comparing the germination of pollen on the open stigma in moist and in dry air, and Lutz states that the pollen on closed stigmas germinates more quickly than on open stigmas. My own work carries considerably further the evidence for the importance to the plant of the secondary closing of the stigma. Lutz claims that secondary closing cannot aid germination because germination has taken place before secondary closing occurs. This result was not true for the plants I used, many of which made the secondary closing two hours after the secondary opening, and in this period pollen had not germinated on the open stigma, even though the stigma had carried through the primary closing. Forty-eight blossoms of Catalpa speciosa showed no germination of pollen on the open stigmas at $22^{\circ}$ to $26^{\circ} \mathrm{C}$. for a period of 24 hours in moderately moist air, while, in a nearly moisturesaturated chamber, there was abundant germination on the open stigmas in the same time and at the same temperature. Similar results were obtained with the open stigmas of Torenia fournieri, Tecoma radicans, and Mimulus cardinalis. Thus it is shown that a moderately moist atmosphere may prevent the stigmas of several species from closing, and at the same time not provide moisture enough to allow germination. Parallel experiments have shown that few or no seeds were produced in Torenia fournieri,

1 This tree was wrongly given the name $C$. bignonioides in my former paper. 
Tecoma radicans, and Mimulus cardinalis when the stigmas were kept open by moderately moist atmosphere, while abundant seeds were formed if the open stigmas were surrounded by a very moist atmosphere. Details of these results may be found in my publication of two years ago. To this evidence may now be added that given by Spathodea campanulata, whose stigmas made no closure at all indoors on the moist Waikiki beach in Honolulu, unless the pollen was applied with pressure. Pollen and pressure together caused closing in 20 minutes. Six and a half hours after pollen was placed on the stigma, 3 stigmas which had closed showed long pollen tubes and plentiful germination, while the 3 which had remained open showed but a few short pollen tubes and the grains generally not swollen. The stigmas of 5 other flowers which had been pollinated in the house $3 \mathrm{I}$ hours before, 3 of the 5 having closed early and so continued while the other 2 had remained continuously open, were examined for germination. All showed pollen tubes, but those in the closed stigmas were much the longer and more numerous. This African tulip tree is native both north and south of the equator, bordering the Gulf of Guinea. The region is not well supplied with rain, and one may well believe that the closing of the stigma after pollination is a matter of the greatest biological import in promoting or insuring pollen germination.

\section{SUMMARY}

The African tulip tree, Spathodea campanulata Beauv., offers evidence supporting that of other plants, that the continued closure of the stigma lobes so as to enclose the pollen promotes, and in dry atmosphere is necessary to, the germination of the pollen.

This species is peculiar in that the sensitiveness of the stigma lobes to pressure is not sufficient to cause more than a slight movement, never to cause closing. The complete closing requires both pollen and pressure, The closing does not take place quickly enough to guard against self-pollination; the distant position of the open stigma would seem, however, to make the possibility of self-pollination remote.

The cause of the second closing of the stigmas, as it takes place in most species, must be related to the amount of moisture in the air, since, in the several species so far tested, the closing does not take place if the air is very moist. When the second closing has taken place, a subsequent opening may be induced by placing the plants in very moist air; at least, this result was obtained with the several species tried, and with Diplacus glutinosus even after 24 hours of continuous closure.

Besides Spathodea campanulata Beauv., Bignonia stans Juss. and Crescentia cujete L. were found to have stigmas sensitive to pressure, the stigmas of the two latter closing completely with pressure alone.

As listed below, only five families have so far been found to include members with stigmas sensitive to contact. The list given in my former paper 
should be revised by crediting the discovery of two species to Koelreuter (4), while others are added from the publications of Treviranus (I I), Morren (8), Trelease (10), Miyoshi (7), and Lutz (6). A sixth family, the Lobeliaceae, was reported by Medicus as having species with sensitive stigmas; but sensitiveness could not be demonstrated by Gärtner (I) nor by Goebel (2). Of the five families in which sensitive stigmas have been reported, no species in the Bignoniaceae and the Martyniaceae have been reported with insensitive stigmas. In the three other families, Torenia exappendiculata in the Scrophulariaceae was found insensitive by Lutz, Acanthus mollis L. in the Acanthaceae by myself, and Utricularia montana, U. uliginosa, and Pinguicula in the Lentibulariaceae by Goebel. All these exceptional cases have the bilabiate stigma characteristic of sensitive stigmas.

In the following list, authors' names are enclosed in parentheses. The Index Kewensis has been employed to eliminate synonyms and to give specific names to two forms for which the authors gave varietal names only.

\section{List of Plants Reported with Sensitive Stigmas}

Bignoniaceae: Tecoma radicans (Koelreuter), T. grandiflora (Heckel), T. stans Juss. (Newcombe); Catalpa bignonioides (Heckel), C. speciosa Warder. (Newcombe); Amphicome arguta (Heckel); Incarvillea delavayi (Burck); I. olgae (Lutz); Spathodea campanulata Beauv. (Newcombe); Crescentia cujete L. (Newcombe).

Scrophulariaceae: Mimulus luteus (Henderson), M. moschatus (Henderson), $M$. [roseus] Lewisii (Henderson), $M$. cardinalis (Henderson), $M$. tillingi (sp. ?) (Burck), M. hybridus (Burck), M. glabratus H. B. et K. var. Jamesii Torr. et Gray (Newcombe), $M$. nepalensis Benth. (Miyoshi), $M$. sessifolius Maxim. (Miyoshi); Mazus rugosus Lour. var. macrantha Fr. et Sav. (Miyoshi); Torenia fournieri (Burck), T. [baillioni] flava (Lutz); Rehmannia sp. (Kerner); Gratiola sp. (Treviranus); Digitalis purpurea L., and $D$. purpurea $\times D$. lanata (Newcombe).

Martyniaceae: Martynia proboscidea (Koelreuter), M. lutea (Heckel), M. fragrans (Burck), M. formosa (Burck), M. tricolor (Lutz); Diplacus glutinosus Nutt. (Henderson).

Acanthaceae: Strobilanthes anisophyllus (Morren), S. isophyllus (Trelease), S. dyerianus (Goebel).

Lentibulariaceae: Utricularia vulgaris (Hildebrand).

University of Michigan, ANN Arbor

\section{BIBLIOGRAPHY}

Other titles of papers on the behavior of sensitive stigmas will be found in the author's paper listed below as number 9 .

I. Gärtner, K. F. Versuche und Beobachtungen über die Befruchtungsorgane der vollkommeneren Gewächse und über die natürliche und künstliche Befruchtung durch den eigenen Pollen. Stuttgart, 1844. 
2. Goebel, K. Organographie der Pflanzenorganen. Ergänzungsband, p. 355. Jena, I920.

3. Hildebrand, F. Weitere Beobachtungen über die Bestäubungsverhältnisse an Blüthen. Utricularia vulgaris. Bot. Zeit. 27: 505. 1869.

4. Koelreuter, J. G. Vorläufige Nachricht von einigen das Geschlecht der Pflanzen betreffenden Versuchen und Beobachtungen. Dritte Vorsetzung. Leipzig, 1766.

5. Lloyd, F. E. Certain phases of the behavior of the stigma-lips in Diplacus glutinosus Nutt. Plant World 14:257. I9I I.

6. Lutz, C. Untersuchungen über reizbaren Narben. Zeitschr. Bot. 3: 289. I9II.

7. Miyoshi, M. Notes on the irritability of the stigma. Jour. Coll. Sci. Tokyo 4: 205. I 89 .

8. Morren, C. Recherches sur le mouvement et l'anatomie du style de Goldfussia anisophylla. Nouv. Mém. Acad. Roy. Sci. Belles-Lett. Brux. I 2: Feb., 1839.

9. Newcombe, F. C. Significance of the behavior of sensitive stigmas. Amer. Jour. Bot. 9: $99 . \quad 1922$.

10. Trelease, $\mathbf{W}$. On the structures which favor cross-fertilization in several plants. Proc. Bost. Soc. Nat. Hist. $21: 433$. I880-82.

I I. Treviranus, L. C. Physiologie der Gewächse, 2. 1838 . 